\title{
Training Trade-Offs in Women's Awareness of Reproductive Health: A Case of Sargodha City (Pakistan)
}

\author{
Dr.Mohammad Iqbal \\ Department of Social Work, University of Sargodha, Pakistan \\ Dr. Yasir Nawaz \\ Department of Sociology, University of Sargodha, Sargodha, Pakistan \\ Dr.Arshad Hussain Hashmi \\ University of Veterinary and Animal Sciences, Lahore, Pakistan \\ Beenish ljaz Butt \\ Department of Social Work, University of Sargodha, Pakistan \\ Asiya Anwar \\ Department of Social Work, University of Sargodha, Pakistan \\ Uzma Ashiq \\ Department of Social Work, University of Sargodha, Pakistan
}

Doi:10.5901/ajis.2014.v3n6p233

\begin{abstract}
Women's awareness of reproductive health depends upon socio-demographic and awareness- related activities of women. The purpose of this study was to evaluate how far these factors determine their awareness. For this purpose, a random sample of 188 women of Sargodha city was selected to study the level of their awareness as predicted by their age, span of married life, household income, education, employment, residential background being socio-demographic factors and frequency of their visits to a qualified doctor, LHWs and training they received as awareness-related activities. The findings of this study revealed that women's age, their household income, their urban background, their span of married life and frequency of their visits to a qualified doctor are strong positive predictors of their awareness at $<0.05$ significance level whereas their being employed and receiving training are negative predictors. It is recommended that situation can be reversed by proper training.
\end{abstract}

Keywords: reproductive health, awareness, training

\section{Introduction}

Good health is one of the pre-requisites of a successful life (Janet and Stabile, 2003; PAVHNA, 2008). It is, according to World Health Organization (WHO), a state of complete physical, mental and social wellbeing and not merely the absence of disease or infirmity (www.who.com). One of the major aspects of health is reproductive health. It is because of the fact that reproductive health, particularly of women, is a sign of healthy household and healthy society. It is essential for the socio-economic development of a country. That was why in 1994, the Cairo Conference on Population and Development agreed on women's reproductive health as an integral part of development. (United Nations,1994).

Among all the 8 MDGs (Millennium Development Goals) the goal 5 exclusively focuses upon women's health. But despite the lapse of 14 years since its ratification status of women's health is low in Pakistan. As far as comparison of Pakistani women with those of their neighboring countries is concerned Pakistan lags behind India and Sri Lanka in both ante-natal care (ANC) and skilled birth attendance (SBA). In Sri Lanka 99\% of women avail ANC whereas the percentage of ANC in 
India and Pakistan is 74 and 61 respectively. Same is the case with SBA. Sri Lanka, consequent upon the high ANC, tops the region with a percentage of 99 ,followed by India with a percentage 47. But a pity for Pakistan who is at 39(UNDP, 2010).Pakistan has very high fertility rate (FR) in the region (i.e.4 births per woman) which is due to its very low contraceptive prevalence (CP)(ibid).FR of Sri Lanka is 2.3 and that of India is 2.8 births per woman whereas CP of Sri Lanka is $68 \%$, of India is $56 \%$ and of Pakistan is $29.6 \%(U N D P, 2009)$ This causes many women to die due to pregnancy and child birth complications, especially in the rural areas.

A number of factors have contributed to keeping the women's health status low in Pakistan. Uphill now, several studies have been conducted on reproductive health of women in Pakistan. A study by Hasan(1982) revealed that absence of an old woman (daddi/nanni) in the household greatly debars the modern women from the requisite awareness of reproductive health. Another study by Karim (1997) supports the idea that due to the cultural constraints women hesitate to share their private problems with others. The other women too cannot replace the well-aware old woman of the past. Still another prominent study conducted by Ghuman(2006) had found that aristocrat Pakistani women are more aware and conscious about their reproductive health than the poor ones.

The above studies were, no doubt, thought-provoking. But we find almost no study about the women of Punjab, especially of Sargodha district, concerning their awareness linked with the socio-demographic variables like age, length of marital life, job, income, and education as well as the awareness-sources like frequency of consulting a doctor and an LHW. In order to fill this gap, we conducted this research to find out the factors responsible for the women's awareness of reproductive health (WARH) in Sargodha. The objectives of this research were:

i) How far socio-demographic factors affect WARH; and

ii) How far awareness-sources(i.e. qualified doctor, LHWs and training from any other source) affect WARH.

The study further justifies itself in a way that Sargodha is among top six districts of Punjab with very high MMR(Maternal Mortality Rate) (Rahim et al, 2006), very low ANC and SBA as a consequence of very low awareness level on the part of women especially in rural areas(Malik,2010).

\section{Methods}

The target population for this study consisted of women of reproductive age(15-49) in Sargodha city. Through multi-stage sampling method, a list of those women who have been receiving gynecological services from any of the following hospitals was prepared:

i. DHQ(Divisional Head Quarter Hospital) Khushab Road;

ii. Hilal-e-Ahmer Hospital, Old Satellite Town;

iii. Maula Bux Hospital, Khushab Road;

iv. Fatima Hospital ,University Road;

v. Ibraheem Hospital, Stadium Road; and

vi. Abbas Hospital, Old Satellite Town

The list consisted of 3500 randomly selected women served as sampling frame of our study. From this sampling frame a random sample, using table of random numbers, was drawn at $95 \%$ confidence level with the help of formula: $\mathrm{n}=\left(\frac{Z S}{E}\right)^{2}$. The final realized sample included 188 women.

The instrument used for this study was an interview schedule administered by some trained workers who could access 181 women in the sample as 7 women could not be traced. The instrument prepared for the purpose was pretested with a convenience sample of 18 women whereas data for the main study was collected during April 2012 to January 2013.

The measure included 16 Likert scale statements of which the scale points were labeled as follows:1=Strongly Disagreed,2=Disagreed,3=Neutral,4=Agreed, and 5=Strongly Disagreed. The other questions aimed at sociodemographic profile of the respondents. The items of Likert scale were randomized in the tool to minimize the impact of order bias. Table 1 indicates which items measured each indicator of women's awareness of reproductive health (WARH) along with respective values of Cronbach's alpha. 
Table 1: Sub-dimensions and items of the measurement scale used to measure women's awareness of reproductive health (WARH)

\begin{tabular}{|l|c|c|}
\hline Sub-dimensions & Items & Cronbach's alpha \\
\hline Awareness about ante-natal care (ANC) & $1,5,9,13$ & 0.81 \\
\hline Awareness about skilled birth attendance (SBA) & $2,6,10,14$ & 0.81 \\
\hline Awareness about fertility rate (FR) & $3,7,11,15$ & 0.80 \\
\hline Awareness about contraceptive prevalence(CP) & $4,8,12,16$ & 0.73 \\
\hline
\end{tabular}

A composite score was calculated for each of the four sub-dimensions by averaging respondent's answers across the items in each sub-dimension. The higher a respondent's composite score was the more she was aware of her reproductive health.

\section{Data Analysis}

Data was analysed using SPSS-17.First descriptive analysis and then bivariate analysis consisting of hypothesis testing was conducted.

\section{Descriptive Analysis}

Descriptive analysis consisted of two parts: Socio-demographic characteristics and awareness-related activities. Both of the parts were separately dealt with. Socio-demographic variables included: age of the respondent, span of married life, employment status, household income, education and residential background whereas the awareness-related activities consisted of: Training received by the respondent, frequency of consulting a doctor and frequency of consulting an LHW as well as awareness itself.

Table 2 provides a socio-demographic profile of the respondents in terms of their awareness of reproductive health. The results indicate that the highest percentage i.e. $43.6 \%$ of the respondents fall in the age range between 30 to 40 years. More than half of the respondents (53\%) have spent their marriage life for 1 to 10 years. Most of the respondents (57.5\%) are employed whereas 44.8\% have their household income between Rs.30, 000 to 60,000.Majority of respondents i.e.58.6\% have their education between primary to FA/FSc and most of them (63.5\%) reside in Sargodha city. Most of the respondents $(60.8 \%)$ did not receive any sort of training on reproductive health awareness. An overwhelming majority of the respondents (81.8\%) are those who visit 2 to 3 times a qualified doctor during their pregnancy whereas $68.7 \%$ are those who visit 1 to 2 times a lady health worker (LHW) during their pregnancy. As far as their level of awareness is concerned majority of women (43.4\%) claim a medium level of awareness. Relationship of awareness with the above socio-demographic was tested by hypothesis testing.

Table 2: Descriptive Analysis

\begin{tabular}{ccc}
\hline Items & Frequencies & P Value \\
\hline Socio-demographic Characteristics & & \\
\hline Age(years) & & $<.001$ \\
$<30$ & $36(19.9 \%)$ & \\
$30-40$ & $79(43.6 \%)$ & \\
$>40$ & $66(36.5 \%)$ & \\
Span of Married Life(years) & $96(53.0 \%)$ & $<.001$ \\
$1-10$ & $71(39.2 \%)$ & \\
$11-20$ & $14(7.8 \%)$ & \\
$21-30$ & $104(57.5 \%)$ & \\
Employment Status & $77(42.5 \%)$ & \\
Employed & & $<.001$ \\
Un-employed & $29(16.0 \%)$ & \\
Household Income(Pakistani Rupees) & $81(44.8 \%)$ & \\
$<30,000$ & $71(39.2 \%)$ & \\
$30,000-60,000$ & & \\
$>60,000$ & &
\end{tabular}




\begin{tabular}{ccc}
\hline Items & Frequencies & P Value \\
\hline Education & & $<.001$ \\
Illiterate & $13(7.2 \%)$ & \\
Primary & $31(17.1 \%)$ & \\
Matric & $28(15.5 \%)$ & \\
FA/FSc & $47(26.0 \%)$ & \\
BA/BSc & $35(19.3 \%)$ & \\
MA/MSc & $27(14.9 \%)$ & \\
Background & & $<.001$ \\
Rural & $66(36.5 \%)$ & \\
Urban & $115(63.5 \%)$ & \\
Awareness-related Activities & & $<.001$ \\
Training Received & & \\
Yes & $71(39.2 \%)$ & \\
No & $110(60.8 \%)$ & \\
One & & \\
Two & $33(18.2 \%)$ & \\
Three & $76(42.0 \%)$ & \\
Frequency of Consulting a Doctor & $72(39.8 \%)$ & \\
Frequency of Consulting an LHW & & \\
One & $60(33.1 \%)$ & \\
Two & $64(35.4 \%)$ & \\
Three & $57(31.5 \%)$ & \\
Low & & \\
Medium & $29(16.1 \%)$ & \\
High & $79(43.4 \%)$ & \\
Total & $57(31.5 \%)$ & \\
\hline \hline
\end{tabular}

\section{Bi-variate Analysis}

The results majorly consisted of nine hypotheses. Table 3 gives the linear regression results.

Table 3: Summary of Bi-variate Analysis

\begin{tabular}{|c|c|c|c|c|}
\hline Sr.No. & Null Hypotheses( $\left.\mathbf{H}_{\mathbf{0}}\right)$ & Beta $(\boldsymbol{\beta})$ & Sig. & Decision \\
\hline 01 & Hypothesis No.1 & 0.782 & $<0.001$ & Rejected \\
\hline 02 & Hypothesis No.2 & 0.518 & $<0.001$ & Rejected \\
\hline 03 & Hypothesis No.3 & -0.499 & $<0.001$ & Rejected \\
\hline 04 & Hypothesis No.4 & 0.634 & $<0.001$ & Rejected \\
\hline 05 & Hypothesis No.5 & 0.165 & 0.026 & Rejected \\
\hline 06 & Hypothesis No.6 & -0.132 & 0.077 & Accepted \\
\hline 07 & Hypothesis No.7 & 0.615 & $<0.001$ & Rejected \\
\hline 08 & Hypothesis No.8 & 0.517 & $<0.001$ & Rejected \\
\hline 09 & Hypothesis No.9 & 0.210 & 0.004 & Rejected \\
\hline
\end{tabular}

\section{Hypothesis Testing}

As is shown in Table3, the following alternative hypotheses were tested against their null hypotheses to accept or reject different claims regarding WARH.

\subsection{Hypothesis No. 1}

The first hypothesis ( $\mathrm{H} 1)$ focused on the relationship between age and WARH.

The null and alternative hypotheses of $\mathrm{H} 1$ are stated below:

Ho: There is no significant relation between age and WARH. 
$\mathrm{H1}$ : There is a significant relation between age and WARH.

The null hypothesis is rejected against the alternative hypothesis. The value of $\beta=0.782$ at $p<0.05$ shows that there is a high strength significant positive relation between age and WARH.

\subsection{Hypothesis No. 2}

The second hypothesis $(\mathrm{H} 2)$ focused on the relationship between span of married life and WARH.

The null and alternative hypotheses of $\mathrm{H} 2$ are stated below:

Ho: There is no significant relation between span of married life and WARH.

$\mathrm{H} 2$ : There is a significant relation between span of married life and WARH.

The null hypothesis is rejected against the alternative hypothesis. The value of $\beta=0.518$ at $p<0.05$ shows that there is a moderately strong significant positive relation between span of married life and WARH.

\subsection{Hypothesis No. 3}

The third hypothesis $(\mathrm{H} 3)$ focused on the relationship between employment status and WARH.

The null and alternative hypotheses of $\mathrm{H} 3$ are stated below:

$\mathrm{HO}$ : There is no significant relation between employment status and WARH.

$\mathrm{H} 3$ : There is a significant relation between employment status and WARH.

The null hypothesis is rejected against the alternative hypothesis. The value of $\beta=-0.499$ at $p<0.05$ shows that there is a moderately strong significant negative relation between employment status and WARH.

\subsection{Hypothesis No. 4}

The fourth hypothesis $(\mathrm{H} 4)$ focused on the relationship between household income and WARH.

The null and alternative hypotheses of $\mathrm{H} 4$ are stated below:

Ho: There is no significant relation between household income and WARH.

$\mathrm{H} 4$ : There is a significant relation between household income and WARH.

The null hypothesis is rejected against the alternative hypothesis. The value of $\beta=0.634$ at $p<0.05$ shows that there is a high strength significant positive relation between household income and WARH.

\subsection{Hypothesis No. 5}

The fifth hypothesis $\left(\mathrm{H}_{5}\right)$ focused on the relationship between education and WARH.

The null and alternative hypotheses of $\mathrm{H}_{5}$ are stated below:

$\mathrm{H}_{0}$ : There is no significant relation between education and WARH.

$\mathrm{H}_{5}$ : There is a significant relation between education and WARH.

The null hypothesis is rejected against the alternative hypothesis. The value of $\beta=0.165$ at $p<0.05$ shows that there is a weak but significant positive relation between education and WARH.

\subsection{Hypothesis No.6}

The sixth hypothesis $\left(\mathrm{H}_{6}\right)$ focused on the relationship between training received and WARH.

The null and alternative hypotheses of $\mathrm{H}_{6}$ are stated below:

$\mathrm{H}_{0}$ : There is no significant relation between training received and WARH.

$\mathrm{H}_{6}$ : There is a significant relation between training received and WARH.

The null hypothesis is accepted against the alternative hypothesis. The value of $\beta=-0.132$ at $p>0.05$ shows that there is no significant positive relation between training received and WARH.

\subsection{Hypothesis No. 7}

The seventh hypothesis $\left(\mathrm{H}_{7}\right)$ focused on the relationship between residential background and WARH.

The null and alternative hypotheses of $\mathrm{H}_{7}$ are stated below: 
$\mathrm{H}_{0}$ : There is no significant relation between residential background and WARH.

$\mathrm{H}_{7}$ : There is a significant relation between residential background and WARH.

The null hypothesis is rejected against the alternative hypothesis. The value of $\beta=0.615$ at $p<0.05$ shows that there is a high strength significant positive relation between residential background and WARH.

\subsection{Hypothesis No.8}

The eighth hypothesis $\left(\mathrm{H}_{8}\right)$ focused on the relationship between average no. of ante-natal consultations with a qualified doctor and WARH.

The null and alternative hypotheses of $\mathrm{H}_{8}$ are stated below:

$\mathrm{H}_{0}$ : There is no significant relation between average no. of ante-natal consultations with a qualified doctor and WARH. WARH.

$\mathrm{H}_{8}$ : There is a significant relation between average no. of ante-natal consultations with a qualified doctor and

The null hypothesis is rejected against the alternative hypothesis. The value of $\beta=0.517$ at $p<0.05$ shows that there is a moderately strong significant positive relation between average no. of ante-natal consultations with a qualified doctor and WARH.

\subsection{Hypothesis No.9}

The ninth hypothesis $\left(\mathrm{H}_{9}\right)$ focused on the relationship between average no. of ante-natal consultations with an LHW and WARH.

The null and alternative hypotheses of $\mathrm{H}_{9}$ are stated below:

$\mathrm{H}_{0}$ : There is no significant relation between average no. of ante-natal consultations with an LHW and WARH.

$\mathrm{H}_{9}$ : There is a significant relation between average no. of ante-natal consultations with an LHW and WARH.

The null hypothesis is rejected against the alternative hypothesis. The value of $\beta=0.210$ at $p<0.05$ shows that there is a weak but significant positive relation between average no. of ante-natal consultations with an LHW and WARH.

\section{Discussion}

To the best of our knowledge, this is the first ever study of its kind in the universe area (Sargodha). The well-thought instrument for this study was unique in the sense that it successfully revealed those facts which were previously hidden or overlooked.

It was revealed that women's awareness of reproductive health is strongly associated with their age. It was found that older women, regardless of their educational qualification claim more awareness as compared to the younger women. Similar relation can also be observed with their household income. Women with higher household income show a greater awareness as compared to those with poor economic status. It is quite obvious that women with higher household income have greater frequency of doctor's visits and more doctors' visits, in turn, causes more awareness.

Education of the respondents gives somewhat interesting fact that awareness is not associated with women's educational qualification. Same is the case with women's response for their training received.

As far their background, women who belong to urban area claim more awareness than those living in the rural area. It may be due to the better medical facilities available in the city of Sargodha. This verifies urban women's more visits to the doctors than their rural counterparts. It means that doctor's visits are a strong predictor of women's knowledge of reproductive health. Then comes the role of LHW. But we find no impact of training. It may be due to the facts that trainings on this issue are not provided in a proper way.

\section{Conclusion and Recommendations}

It can be concluded from this study that a woman whose age is between 30-40 years, whose span of married life is between 1-10 years, whose household income is between Rs.30,000-60,000, who belongs to the urban area of Sargodha(no matter what her educational level is and whether she visits an LHW or not)but visits a qualified doctor twice or thrice within a period of three months prior to her delivery, is supposed to have more awareness than those of otherwise. 
On the other hand, her being employed and having received a training of reproductive health affects her awareness adversely. It doesn't mean that women who are employed should quit their jobs for the sake of reproductive health awareness and to bid farewell to trainings. One should devise ways to make them fruitful and especially beneficial to the employed women.For this purpose following aspects of training must be properly kept in focus:
i. Frequent Trainings
ii. $\quad$ Proper Preparations
iii. Expert Trainers
iv. Adequate Timings
v. Accessible venue
vi. Publicity
vii. Incentives
viii. $\quad$ Proper budget for training

\section{References}

Currie, Janet and Mark Stabile. (2003). Socioeconomic Status and Health: Why is the Relationship Stronger for Older Children? American Economics Review 93, No. 5:1813-23.

Ghuman, S., Lee, H. \& Smith, H. (2006). Measurement of Women's Autonomy According to Women and their Husbands: Results from Five Asian Countries. Social Science Research, 35: 1-28.

Hasan, Dr. Iftikhar N.(1982).Psychological Profile of Rural Women. Islamabad: Ministry of Women Development, Social Welfare and Special Education

Karim, M.S. (1997). Reproductive Behavior in Muslim Countries. New York: UNFPA

UNDP (United Nations Development Programme).(2009).Human Development Report 2010.New York: United Nations

UNDP (United Nations Development Programme).(2010). Human Development Report 2009. New York: United Nations

United Nations (UN). (1994). Report of the International Conference on Population and Development, Cairo, 5-13 September, 1994. New York: United Nations

PAVHNA (2008) Enhancing Women's Empowerment through strengthening reproductive health programs of NGO's in Pakistan. Online at http://pavhna.com. Retrieved on 9.10.11

Rahim R; Shafqat T. and Faiz N.R.(2006). An Analysis of Direct Causes of Maternal Mortality. Karachi: Jinnah Postgraduate Medical Institute

Government of Pakistan.(2011). Punjab Development Statistics 2011. Lahore: Bureau of Statistics 
